\title{
Study on the application of MOOC in the teaching practice of College Physical Education Course
}

\author{
Zhiwen Pi \\ Department of Physical Education, Hubei University of China Medicine, Wuhan City, Hubei Province, \\ 430065, China
}

Keywords: MOOC; College sports; Teaching practice; Application

\begin{abstract}
MOOC (Massive Open Online Course) is a large-scale open online course rising in recent years, and it is a new teaching mode that can promote the transformation of higher education idea and way. Based on the author's study and work experience, this paper discussed the application of MOOC in the teaching practice of college physical education curriculum. This paper first analyzed the agreement of MOOC and college physical education teaching, and then put forward the application path of MOOC in the teaching practice of college physical education curriculum, and finally proposed the design principle of MOOC teaching mode.
\end{abstract}

\section{Introduction}

At present, many universities in China have joined the world's three largest platforms or self built platforms. Academia has different opinions on MOOC's challenges and impacts on traditional universities. College physical education is a curriculum for colleges and universities in China. While, the problems concerning how to comply with the requirements of the times with the new teaching mode of MOOC, changing traditional teaching methods and effectively promoting university physical education and improving teaching quality has become an important and urgent topic at present. Based on the actual situation of MOOC and traditional physical education, this paper analyzed the application of MOOC in college physical education, and provided some reference for promoting the reform of college physical education.

\section{The Agreement between the MOOC and the College Physical Education}

It is determined by its own advantages that it is possible to set off a storm of "educational reform" in the Chinese educational world. At present, MOOC has accepted actively responses and development in China. Experts and scholars in the field of education show great interest and make a positive attempt on the way of "MOOC". College physical education teaching is the last stage for students to learn sports knowledge before they go to work. It is also a critical period to cultivate students' awareness of lifelong physical exercise. In college physical education, we must improve students' knowledge level as the starting point, maximize students' knowledge and maximize their social comprehensive ability, so that they can become useful talents for the future country and society. In college physical education, college students are influenced by boring teaching content, limited field equipment, inadequate school teachers and other factors, which can not stimulate the enthusiasm of college students in physical training. Traditional teaching methods have not been able to bring learning motivation to college students in the new era. However, the emergence of MOOC has brought new research directions to the teaching mode of college physical education, and promoted the reform of existing college physical education teaching mode. College physical education has the characteristics of many sports items, strong technical nature and need to repeat the practice. MOOC can explain and demonstrate teaching elements such as text, voice, image, video and so on. It can integrate teachers' teaching resources, expand their learning vision, and stimulate their interest in learning and autonomous learning. It can break the limitations of time and space, so that the learners can learn independently, practice independently; because the time of the course is short, and the content is refined and the focus is outstanding, it is easy to master. In addition, the 
repeatability of MOOC helps college students prepare for lessons before class and after class, for example, when learning technology, it can help college students intuitively learn and understand the key points and difficulties of a technical action. Thus, in the time of rapid development of the "Internet plus", the characteristics and advantages of MOOC can promote the teaching of college physical education.

\section{The Application Path of MOOC in the Teaching Practice of College Physical Education Course}

\subsection{Video learning before class}

Video learning before class is the basic knowledge preparation stage of classroom training internalization, and the good or bad effect of learning directly affects the classroom training. First of all, according to the characteristics of physical education curriculum, teaching objectives and knowledge system requirements, physical education teachers design the development projects of MOOC platform, arrange teaching activities, and design basic knowledge and training contents for each class according to the idea of "anti technology". Then, the teachers make the theoretical knowledge to streamline the video and upload the MOOC platform, and arrange the students to watch the teaching video before class and complete the training and test of the knowledge points. In accordance with the learning tasks assigned by the teachers and the needs of individual needs, students complete autonomic learning through making progress, rhythm, speed and way of learning from the master. Good students can learn faster and poorly learning students can slow down or repeat video learning. The physical education teacher designs the questions before the knowledge point explanation, so that to lets the student complete the the training questions; the test result will pass through the network system instantly to the student. Of course, students will have a lot of questions. Then, the students organize the results and questions of the training, bring them into the classroom and ask the teachers to question them or communicate with the teachers through the class. Taking the teaching of college sports volleyball front digging as an example, the teacher unload his volleyball videos on the MOOC platform so that students can watch and learn. In addition, the teacher put up the method and the matters needing attention into exercises. After the students have finished the video, they have finished the action and provide strengthening training for students, for example, setting digging batting position and the hand position of digging as exercises.

\subsection{Internalization of classroom training}

First of all, physical education teachers answer questions raised by students before class, or explain pertinent knowledge points pertinence according to students' feedback or theoretical knowledge test before class. Then, in accordance with the pre designed classroom activities, the physical education teachers simply introduce the course goals and guide the students to understand the goals and tasks of the project. Finally, they set up a training team and set up a team of learning and training teams with $4 \sim 6$ as a team. Each team selected a team leader. The team leader is responsible for the assignment of tasks, knowledge mastery and quality control, and teachers check the knowledge of each group. During training, students can experience, feel and understand knowledge. When they encounter problems, they can learn from each other and discuss together, or communicate with teachers one by one or more than one. For the common problems existing in the students, teachers can unify their demonstrations and solve them collectively. Physical education teachers should continue to guide students deep thinking when they answer student questions and make appropriate coaching knowledge. Through the process of "training, discussion, questioning, coaching and retraining", students will improve themselves and finally this can increase the interest of the classroom through competitions among the teams, which is also in line with the characteristics of sports teaching. After turnover og the physical education class, it increases the contact time of inter-activeness and individuation between teachers and students, and sports teacher is no longer superior of the saints, and students are no longer obedient believers. Classroom has become the place where students go through training and solve problems. Students have been 
adhering to the teaching idea of Mr. Tao Xingzhi in "learning in doing and doing in learning", and have completed the internalization of knowledge to the maximum. Taking the university sports volleyball from digging teaching as an example, before class, volleyball teachers tell students the teaching goals and tasks of this class, and solve the problems raised by the students after watching video teaching before class; further, the teacher divided the students into several groups since set up training, and guide or give individual guidance. Through the training, they carry on digging matches between the teams, which will not only increase the spirit of the teamwork of the students, but also stimulate the students' interest in serious training. At the end of each class, the teacher summarizes, reviews and arranges the content of the next class in the quality and quantity of the student's completion of the action.

\subsection{Post class immobilization}

After class, each student revisited the mistakes in the training process, reviewed and reflected the summary and evaluation made by the teachers in the classroom, especially for those who didn't have good skills in class competition should strengthen training after class. In this way, every student can keep up with the predefined goals in the teacher's teaching so as to facilitate the better study of subsequent knowledge.

\section{The Design Principles of MOOC Teaching Mode}

\subsection{Course length}

The MOOC and the flipping class are different from the traditional physical education classes. The number of hours per week can be flexible and varied. Physical education teachers can take "week" as a measure unit of the course, and it can be different from the traditional physical education teaching when the number of class weeks is designed. Video content can be divided into short units of $8 \mathrm{~min} \sim 12 \mathrm{~min}$, each of which represents a coherent concept. Students can learn these materials in different ways, and the specific learning situation depends on their background, skills and interests. For example, some students benefit from a part of the material, but other students may know less about this part of the material. For example, volleyball curriculum is considered as a part of the middle school entrance examination. Other students may be interested in some of their knowledge or they haven't been touched before, so they want to explore it alone. Therefore, this model can escape the "one knife" education method, and more allow students to follow the more personalized curriculum. It is suggested that the number of weeks in the course should not be too long, which is one quarter of the total number of courses.

\subsection{Teaching videos}

Research shows that students can only maintain $10 \mathrm{~min}$ to $12 \mathrm{~min}$ when watching video. Many MOOCs and flipped classes platforms are doing very thoughtful data analysis. Once the video is too long, the number of people will drop sharply, and the shorter time means attention can be more concentrated. So, if the teaching video is recorded in 50min on the basis of the traditional course, the effect will be very bad. For this reason, we split the elective course of college sports into several units, and let the students review the small units through the platform before the weekly physical education. Video content is a short unit of $8 \mathrm{~min}$ to $12 \mathrm{~min}$, and each unit represents a coherent concept. Now the video length of the students is getting shorter and shorter, and the development of the class is becoming more and more fragmented in the future.

\subsection{Discussion area}

As students who choose physical education class will form a specific learning crowd on the Internet, teachers need to establish discussion areas as the forum. The discussion area designed by the physical education teacher should have the flexibility and space, so that to guide the emergence of the learning forum and the discussion between students. From the observation of many MOOCs and flipped class platforms, it is found that he should first let learners participate in it when a student asks questions. After that, teachers can provide reasonable answers. The process of 
producing the correct answers through the process of discussion is often the process of learning to be absorbed and understood.

\section{Conclusion}

As an important part of higher education, college physical education has practical characteristics. As a kind of auxiliary, MOOC is a good supplement to the teaching of physical education in the university, and it can not replace the traditional physical education teaching. Under the background of MOOC, the teaching of college physical education should regard student study as the main goal and improves students' autonomous learning ability. Physical education teachers should keep pace with the times, innovate teaching models and strive to improve their knowledge structure and teaching ability, so that to improve the quality and effect of college physical education.

\section{References}

[1] Lei Min. Analysis of the Present Situation of the Information Construction of Physical Education Courses in Chinese Universities[J]. Journal of Physical Education, 2017 (03): 101-105.

[2] Fu Wei. A Study on the Application of MOOC in the Teaching of Physical Education[J]. Sports World (Academic Edition), 2017, (05): 138-139.

[3] Wang Rui, Dong Chaowu, Han Liang, Yang Chenxi. Study on the Construction of the Teaching Mode of "MOOC" in Physical Education in Colleges and Universities[J]. Intellect, 2017, (10): 134-135.

[4] Chen Dong. Research on the Teaching of College Physical Education under the Background of MOOC[J]. Journal of Higher Education, 2016 (22): 92-93.

[5] Jiang Xianghua. Study on the Application of MOOC in the Teaching Practice of College Physical Education Curriculum[J]. Contemporary Sports Science and Technology, 2015, (33): 132-133.

[6] Li Fang, Yin Long, Shen Zhuoling. Challenges and Opportunities: the Enlightenment of MOOC on the Teaching of Physical Education in University[J]. Sports Scientific Research, 2015, (05): 100-103.

[7] Zhang Guodong, Wang Xiaotang. Study on the Application of MOOC in the Teaching Practice of College Physical Education Curriculum[J]. Journal of Career Academy, Jiamusi, 2015, (08): 366. 